\title{
Adenosine Inhibits Excitatory but Not Inhibitory Synaptic Transmission in the Hippocampus
}

\author{
Kong-Woo Yoon ${ }^{1,3}$ and Steven M. Rothman ${ }^{1,2}$ \\ Departments of ${ }^{1}$ Anatomy and Neurobiology and ${ }^{2}$ Pediatrics, Washington University School of Medicine, St. Louis, \\ Missouri 63110 and ${ }^{3}$ Division of Neurosurgery, St. Louis University School of Medicine, St. Louis, Missouri 63110-0250
}

\begin{abstract}
We examined the effects of adenosine and baclofen on inhibitory (IPSC) and excitatory (EPSC) synaptic currents in dissociated rat hippocampal neurons. Adenosine dramatically reduced monosynaptic EPSCs but failed to diminish IPSCs. This selective effect on EPSCs is likely due to inhibition of excitatory transmitter release because adenosine did not directly alter any properties of postsynaptic neurons. Baclofen depressed both EPSCs and IPSCs to approximately the same extent. These experiments indicate that the presynaptic effects of adenosine and baclofen are clearly separable and that transmitter sensitivities of inhibitory and excitatory neurons can differ. These differences could be exploited in the design of antiepileptic drugs that act at adenosine receptors to limit excitatory neurotransmission without blocking tonic inhibition.
\end{abstract}

Adenosine may affect CNS function by inhibiting synaptic release of neurotransmitters (Dunwiddie, 1985; Fredholm and Dunwiddie, 1988). This may be explained by at least two separate physiological effects of adenosine. First, adenosine increases a potassium conductance that is modulated by a G-protein (Trussell and Jackson, 1985, 1987). Second, voltagegated calcium currents in peripheral neurons are directly blocked by adenosine (Dolphin et al., 1986; Macdonald et al., 1986). At a nerve terminal, either mechanism could reduce calcium entry and subsequent transmitter release. It is not clear whether adenosine also antagonizes calcium currents in central neurons (Gerber et al., 1989; Scholz et al., 1989). Despite gaps in our knowledge about adenosine's biophysical effects on transmitter release, there is firm biochemical and physiological evidence that it limits the release of some transmitters in the CNS. For example, adenosine reduces potassium-stimulated release of glutamate and aspartate in hippocampal slices and also blocks excitatory synaptic responses in hippocampal slices and cultures (Schubert and Mitzdorf, 1979; Burke and Nadler, 1988; Fredholm et al., 1989; Scholz et al., 1989). Information about adenosine effects on GABA release is conflicting. While some investigators suggest that adenosine reduces GABA output (Hollins and Stone,

Received Oct. 1, 1990; revised Dec. 12, 1990; accepted Dec. 19, 1990.

We are indebted to Drs. Kenneth Scholz and Richard J. Miller for making available unpublished results. We would also like to thank Drs. Jeanne Nerbonne and Laurence Trussell for critiquing earlier drafts of the manuscript, Nancy Lancaster for culture preparation, and Deborah Howard for secretarial assistance.

This work was supported by the McDonnell Center for Cellular and Molecular Neurobiology (K.-W.Y.) and by NIH Grants NS 19988 and NS 14834.

Correspondence should be addressed to Steven M. Rothman, M.D., Department of Anatomy and Neurobiology, Washington University School of Medicine, 660 South Euclid Avenue, Box 8108, St. Louis, MO 63110.

Copyright (C) 1991 Society for Neuroscience 0270-6474/91/111375-06\$03.00/0
1980), others failed to detect an effect (Burke and Nadler, 1988). During the course of experiments examining the modulation of neurotransmitter release in cultured neurons, we have made a series of observations that provides an extremely interesting resolution to this conflict.

\section{Materials and Methods}

We used dissociated 1-d-postnatal rat hippocampal cell cultures 5-12 $\mathrm{d}$ in vitro for all experiments. Details of culture methods have been described elsewhere (Yamada et al., 1989). The tight-seal, whole-cell recording technique (Hamill et al., 1981) was used to voltage clamp postsynaptic cells and intracellularly stimulate presynaptic cells. The culture medium was exchanged with extracellular fluid containing (in mM) $\mathrm{NaCl}$ (140), $\mathrm{KCl}$ (3), Na HEPES (10), glucose (5.5), $\mathrm{CaCl}_{2}$ (4), and $\mathrm{MgCl}_{2}$ (4), with $\mathrm{pH}$ adjusted to 7.3 . The electrodes were fabricated by pulling glass capillaries (1.2-mm outer diameter) in two steps. Series resistance was usually $10-15 \mathrm{M} \Omega$. The intracellular solution contained (in mM) $\mathrm{K}$ isethionate (138), $\mathrm{KCl}(2)$, Na HEPES (10), EGTA (1.1), glucose (4), and ATP- $\mathrm{Mg}_{2}$ (2). With these solutions, inhibitory postsynaptic currents (IPSCs) reversed at $-70 \mathrm{mV}$, and excitatory postsynaptic currents (EPSCs) at above $0 \mathrm{mV}$ (Fig. 1). All pipette solutions were adjusted to $\mathrm{pH} 7.2$, and experiments were done at room temperature. Currents and voltage signals were digitized at $1 \mathrm{KHz}$ for off-line analysis.

We obtained synaptic pairs by simultaneously recording from two nearby neurons within a microscope field. None of the presynaptic cells required current injection to maintain a stable resting membrane potential and action potential that peaked above $0 \mathrm{mV}$. A depolarizing current of 5-msec duration was injected through a balanced bridge into the presynaptic cell to initiate an action potential. A pair of cells was considered monosynaptically connected if an action potential in one cell always elicited a postsynaptic current in the second cell and if there was less than a 5-msec delay between presynaptic action potential peak and onset of postsynaptic current. Some drugs were added to extracellular fluid by whole-bath perfusion. The fluid in the culture dish (about $0.5 \mathrm{ml}$ ) was cxchanged manually with syringe and continuous vacuum suction. To assess effects of drugs, five consecutive synaptic currents ( 5 sec apart) were averaged and compared in the absence and presence of drug. After return of control solution, any synaptic pair showing a decline in current greater than $25 \%$ of control was deleted from analysis. In some experiments, drugs were applied directly onto the cell bodies by glass capillary tubes with 1-2- $\mu \mathrm{m}$ tip diameters. After filling the capillaries with desired solutions, they were connected to an air pressure source (10 psi) and gated by a square-wave pulse of $10-20$-msec duration. The tip of capillary was placed at the position where the maximum current was elicited, usually $5-10 \mu \mathrm{m}$ from the cell surface. The drug responses are expressed as percent of the current peaks obtained in the normal extracellular fluid. The numerical data are expressed as mean \pm standard error, and significance was tested by two-tailed or paired $t$ tests according to the appropriatencss of comparison. All drugs were obtained from Sigma (St. Louis) except for $( \pm)$-baclofen, which was a gift from Ciba Geigy.

\section{Results}

All monosynaptic EPSCs were attenuated by adensosine (10$100 \mu \mathrm{M}$; Figs. 2, 3). On average, the peak EPSC declined to 21.9 
Figure 1. A, A synaptically connected pair of neurons with both an excitatory and an inhibitory component in the postsynaptic current. The voltage trace of the presynaptic action potential is depicted above the current traces of the postsynaptic cell. The presynaptic cell is an excitatory cell that directly synapses on the postsynaptic cell. It also excites an inhibitory neuron that in turn synapses on the postsynaptic cell with a disynaptic delay. The recording pipette contained $2 \mathrm{~mm} \mathrm{Cl}$, with $E_{\text {rev }}$ for the IPSC at around $-70 \mathrm{mV}$. The postsynaptic cell was held at $-90,-80,-70$, -60 , and $-50 \mathrm{mV}, B, I-V$ plot of the traces in $A$. At the holding potential of $-60 \mathrm{mV}$, the IPSC is outward, and EPSC inward.

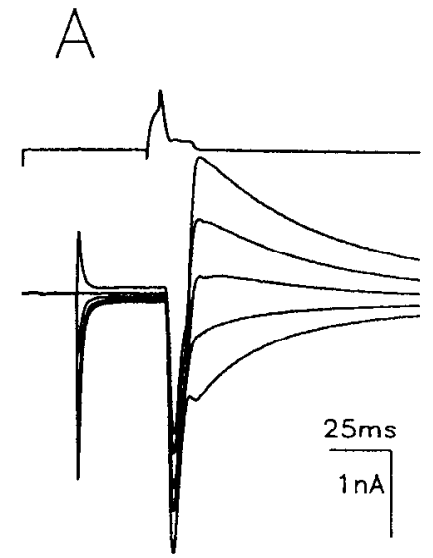

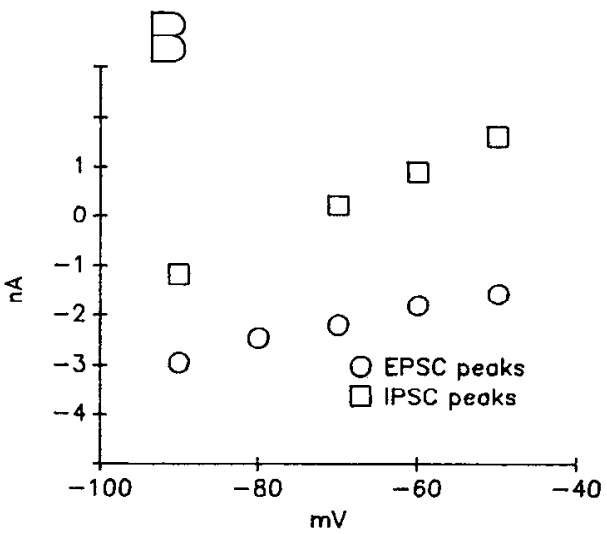

$\pm 4.2 \%$ (mean $\pm \mathrm{SEM} ; n=7 ; p<0.001$ ) of control at $100 \mu \mathrm{M}$. Surprisingly, adenosine, even at this high concentration, had no significant effect on the IPSCs (Fig. $2 B$ ). On average, the peak IPSC during bath application of adenosine was $90.8 \pm 7.1 \%$ of control ( $n=9 ; p>0.1)$. In separate experiments using a lower adenosine concentration, we examined the effect of the adenosine antagonist theophylline. Adenosine at $10 \mu \mathrm{M}$ reduced EPSCs to $23.1 \pm 5.0 \%$ of control, and this effect was largely reversed by coapplication of theophylline $(500 \mu \mathrm{M}$ in all experiments) to $96.9 \pm 4.6 \%(n=3 ; \mathrm{p}<0.001$; Fig. 3$)$. Theophylline therefore attenuates the adenosine block of EPSCs, suggesting that specific adenosine receptors, likely of the $A_{1}$ subtype, mediate this block
(Fredholm and Dunwiddie, 1988). At a higher adenosine concentration $(50 \mu \mathrm{M})$, attenuation of the adenosine effect by theophylline $(500 \mu \mathrm{M})$ was limited to $38.1 \pm 4.3 \%$ of control compared to $19.6 \pm 4.0 \%$, consistent with the low potency of theophylline (Fig. $3 B$ ). Of note, there was no significant difference in adenosine effect between 10 and $100 \mu \mathrm{M}$, indicating that the response has saturated by $10 \mu \mathrm{M}$ (Fig. $2 C$ ).

In an attempt to determine the mechanism of adenosine action, we measured the effect of adenosine on the resting potentials of inhibitory and excitatory neurons during the synaptic pair experiments. The average resting membrane potential of the excitatory cells was $-82 \pm 4 \mathrm{mV}$ before and $-85 \pm 4 \mathrm{mV}$
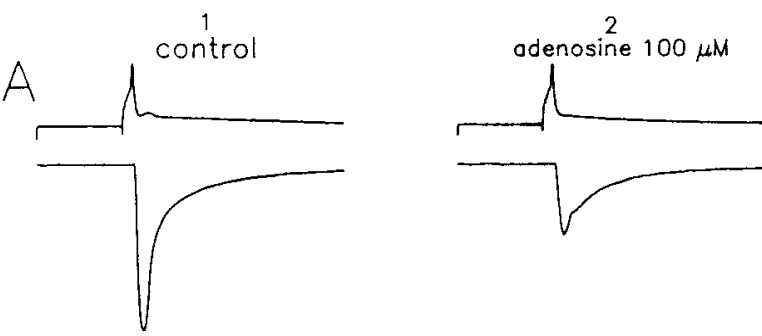

2
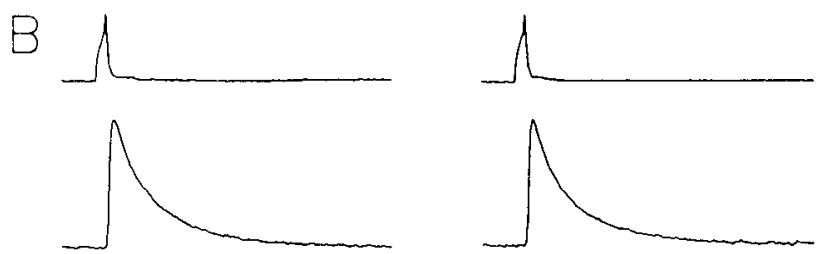
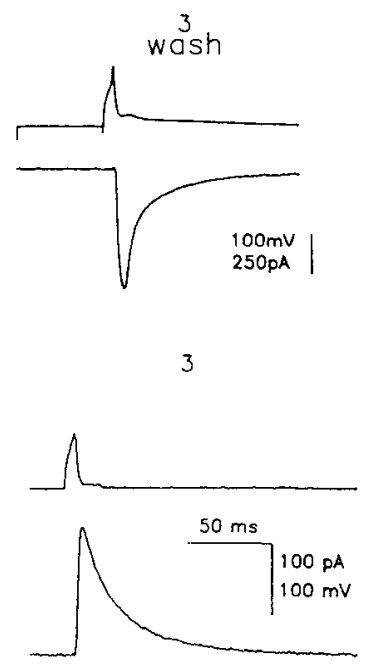

Figure 2. Adenosine selectively blocks EPSCs but not IPSCs. $A$, A typical EPSC response to $100 \mu \mathrm{M}$ adenosine. With bath application of adenosine, the peak of this inward current is attenuated (2). The corresponding presynaptic action potential traces are depicted above each current trace. $B$. A typical IPSC response to the same concentration of adenosine. In both experiments, the postsynaptic cells were held at $-60 \mathrm{mV}$. Each current and voltage trace is the average of five consecutive sweeps (5 sec apart). The time calibration is the same for $A$ and $B$. C, Comparison of the effects of adenosine at 10,50 , and $100 \mu \mathrm{M}$ on EPSCs. There is no concentration dependence over this range of adenosine. The number of cells tested is noted above each bar. Error bars represent SE.

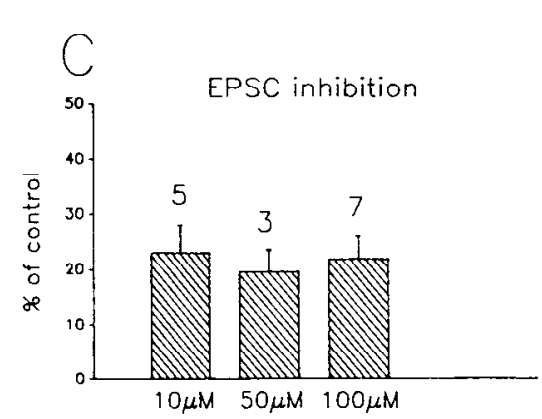



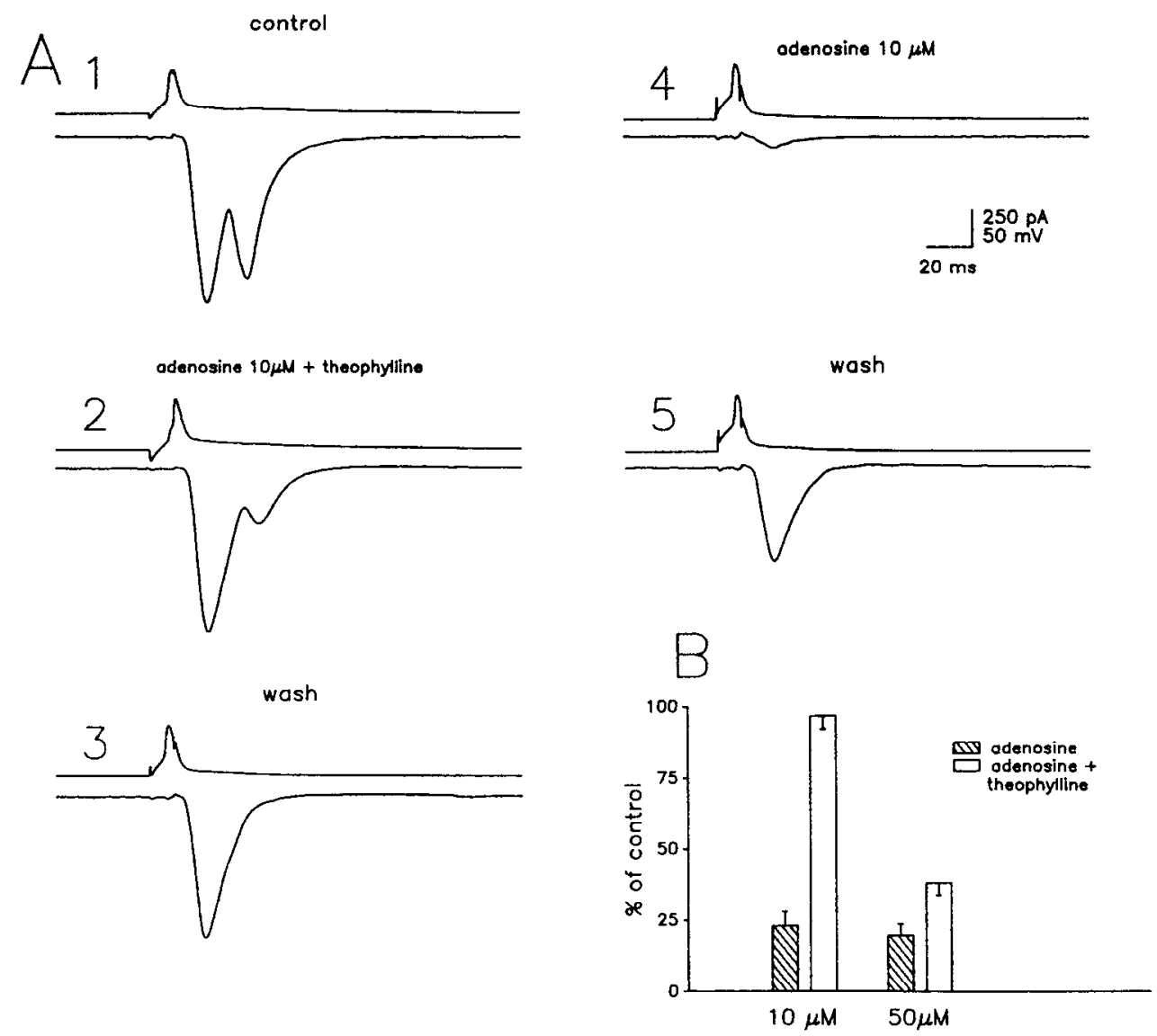

Figure 3. $A$, The effect of adenosine is attenuated by theophylline. $A_{1-5}$ depicts the presynaptic voltage traces and postsynaptic current traces of the same pair of cells during a sequence of drug applications. Theophylline $(500 \mu \mathrm{M}$ in all experiments) almost completely abolishes the effect of $10 \mu \mathrm{M}$ adenosine. Each trace is the average of three sweeps. The second synaptic current $\left(A_{l, 2}\right)$ was not elicited in all three sweeps making up the average. $B$, The bar graph represents the change in the effect of adenosine (10 and $50 \mu \mathrm{M}$ ) with and without theophylline $(500 \mu \mathrm{M})$. Note that there is no significant difference in the adenosine effect at 10 and $50 \mu \mathrm{M}$, but theophylline is much more effective in blocking 10 $\mu \mathrm{M}$ adenosine. Error bars represent SE.

( $n=12)$ during bath application of adenosine $(p>0.2$, paired $t$ test). The average resting membrane potentials of the inhibitory neurons changed from $-72 \pm 3 \mathrm{mV}$ to $-70 \pm 3 \mathrm{mV}(n=$ 9 ) with adenosine ( $p>0.1$, paired $t$ test). Thus, adenosine is not merely hyperpolarizing excitatory neurons. Even at this high concentration of adenosine, no other significant postsynaptic effects were observed. The average chord resistance of neurons receiving excitatory synaptic inputs changed from $232.9 \pm 90.8$ $\mathrm{M} \Omega$ to $241.5 \pm 100.5 \mathrm{M} \Omega$ (range, $-5.3 \%$ to $+10.0 \%$ change with adenosine). The postsynaptic cells receiving inhibitory connections also had insignificant chord resistance changes from $236.8 \pm 36.5 \mathrm{M} \Omega$ to $228.1 \pm 33.3 \mathrm{M} \Omega$ (range, $-24.7 \%$ to $+27.6 \%$ change with adenosine). No significant correlation between changes in chord resistance and the adenosine reduction of synaptic currents was seen in either group (Fig. 4A,B).

While the insignificant effects of adenosine on passive neuronal properties combined with the marked differences in attenuation of excitatory and inhibitory currents argue strongly against a postsynaptic site of action of adenosine, we were concerned that our findings could still be an artifact of faulty space clamping of distal synapses. This could come about if excitatory synapses were located at sites electrotonically distant from the cell body while inhibitory synapses were on the cell soma. Two additional observations make this extremely unlikely. First, when EPSCs inhibited by adenosine were scaled to the same size as controls, their time courses superimposed almost exactly (Fig. $5 A, B)$. If adenosine altered the cable properties of postsynaptic neurons, this would not be expected. Second, when glutamate, the likely excitatory neurotransmitter in our cultures (Rothman and Samaie, 1985; Yamada et al., 1989), was directly applied to neurons at concentrations between 30 and $300 \mu \mathrm{M}$, the currents were not diminished by adenosine (Fig. 5C).

These experiments indicate that adenosine selectively diminishes EPSCs but not IPSCs, likely by differentially inhibiting the release of excitatory neurotransmitter. Adenosine can still diminish polysynaptic IPSCs, which are indirectly triggered by an initial EPSC on an inhibitory interneuron. We found two examples of such a situation in our paired recordings where an evoked monosynaptic EPSC was followed by a likely disynaptic IPSC (Figs. 1, 6). Both were reduced by adenosine. This could be a mechanism for limiting GABA release in vivo where feedforward and feedback inhibition are triggered by excitatory synapses.

In order to determine whether the adenosine observations would generalize to other presynaptic receptors, we studied the effect of baclofen (50-100 $\mu \mathrm{M}$; racemic mixture) on inhibitory and excitatory pairs. Baclofen significantly reduced the synaptic currents of both excitatory and inhibitory connections (Fig. 7). EPSCs were reduced to $21.9 \pm 2.4 \%(n=6)$ of control, and IPSCs were reduced to $29.1 \pm 5.3 \%(n=5)$ of control at 100 $\mu \mathrm{M}$ and $29.2 \pm 7.5 \%(n=5)$ of control at $50 \mu \mathrm{M}$, confirming a number of other reports that baclofen blocks transmitter release (Westbrook and Pun, 1983; Harrison, 1990). We observed small changes in the passive membrane properties of the postsynaptic or presynaptic cells with baclofen, but these cannot account for the decreases in synaptic currents. The average chord resistance of postsynaptic neurons was $275.8 \pm 23.4 \mathrm{Mg}$ before and 278.4 $\pm 24.6 \mathrm{M} \Omega$ during baclofen $(100 \mu \mathrm{M})$ application $(n=10)$. IPSCs 

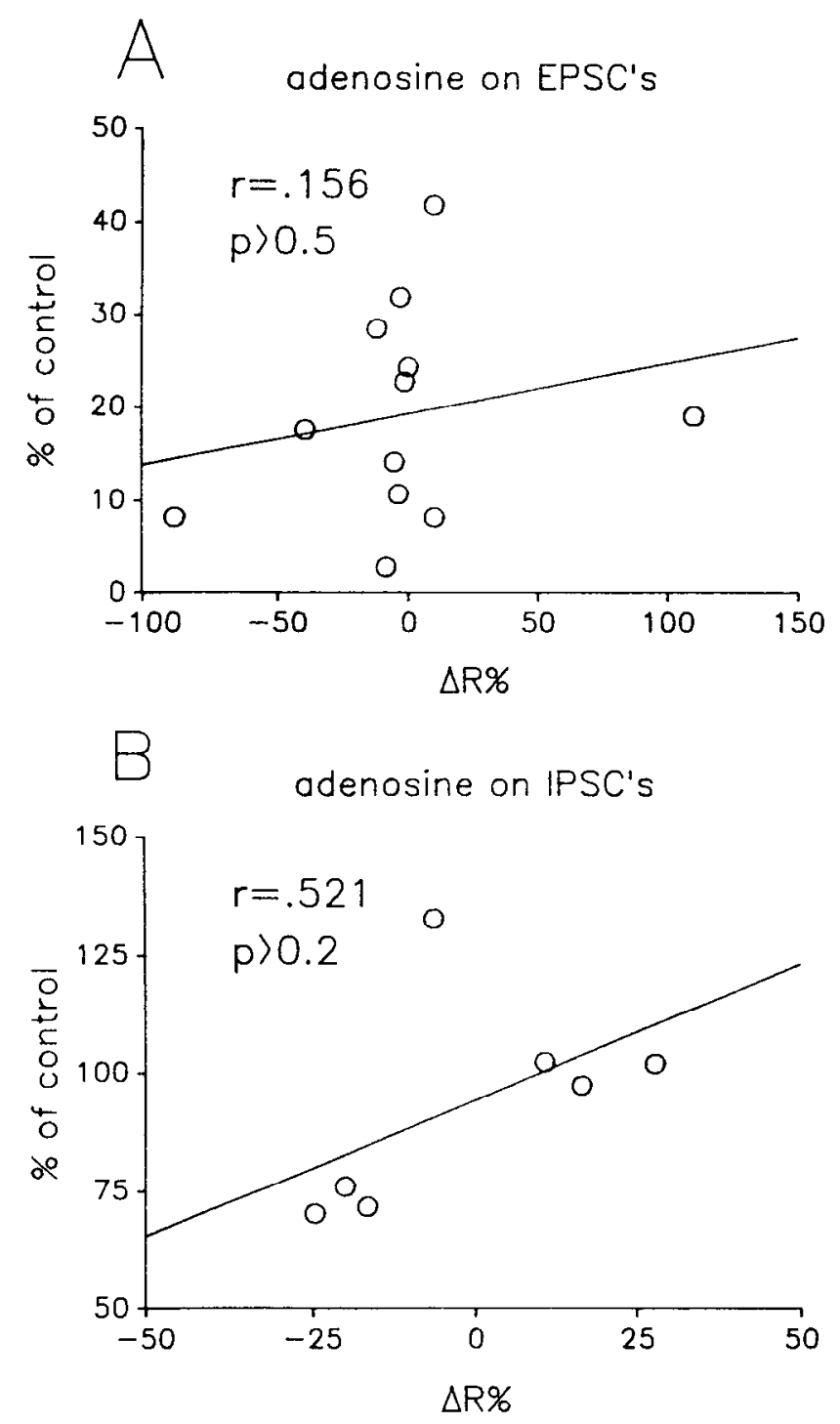

were reduced in amplitude without any shift in the reversal potential (Fig. 8). In excitatory neurons, the average resting membrane potentials were $-78 \pm 3 \mathrm{mV}$ before and $-78 \pm 3$ $\mathrm{mV}$ during baclofen $(n=9)$. In inhibitory neurons, the average resting membrane potentials were $-63 \pm 5 \mathrm{mV}$ before and -61 $\pm 6 \mathrm{mV}$ during baclofen $(n=6 ; p>0.2)$. Of interest, the resting potentials of inhibitory neurons averaged over all groups were more depolarized $(-67 \pm 3 \mathrm{mV} ; n=21)$ than those of the excitatory neurons $(-80 \pm 2 \mathrm{mV} ; n=27 ; p<0.001)$.

\section{Discussion}

Our observations confirm that adenosine can attenuate synaptic activity. In our cultures this effect is restricted to excitatory, glutamatergic neurons (Rothman and Samaie, 1985; Yamada et al., 1989) and is clearly distinct from presynaptic inhibition by baclofen. In addition, our results provide further support for the hypothesis that excitatory and inhibitory neurons are physiologically very different.

The precise mechanism of adenosine action has not been determined by our experiments. However, the evidence is very compelling that the site of action of both adenosine and baciofen is presynaptic in our cultures. First, in the cultured neurons, neither adenosine nor baclofen had a very large influence on passive membrane properties. Although a G-protein-coupled potassium channel has been identified in cells similar to ours (Trussell and Jackson, 1985, 1987; Nicoll, 1988), it is inconsistently expressed in culture such that responses may vary among platings or be absent altogether (L. O. Trussell, personal com-

Figure 4. The postsynaptic changes caused by adenosine $(100 \mu \mathrm{M}) \mathrm{did}$ not correlate with its effect on the synaptic currents. $A$, The change in the chord resistance of the postsynaptic neurons had no significant correlation with the adenosine effect on EPSCs. The correlation coefficient in this plot is 0.156 , with $p>0.5 . B$, The correlation coefficient for the IPSCs is 0.521 , with $p>0.2$. Note that adenosine had no effect on IPSC amplitudes.
$A$

$$
1
$$
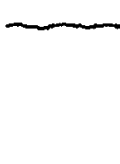

control

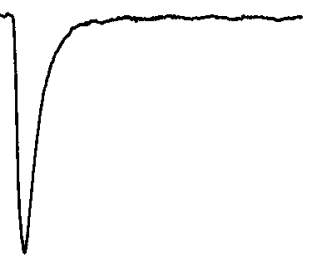

Figure 5. Adenosine does not alter the configuration of the EPSC. $A$, The two traces are EPSCs from the same cell before $(1)$ and after (2) adenosine $(50 \mu \mathrm{M}$ application). $B$, When the second trace was scaled to match the peak of the control trace (which also increases the noise level), both traces superimposed with identical rise times. $C$, The effect of adenosine (100 $\mu \mathrm{M}$ in bath) on current elicited by application of glutamate $(30,100$, and $300 \mu \mathrm{M})$. Three consecutive applications ( $30 \mathrm{sec}$ apart) were averaged in control bath, followed by addition of adenosine into the bath. Values are average percent current elicited in adenosine bath compared to control. Error bars represent SE $(n=5$ in all groups).
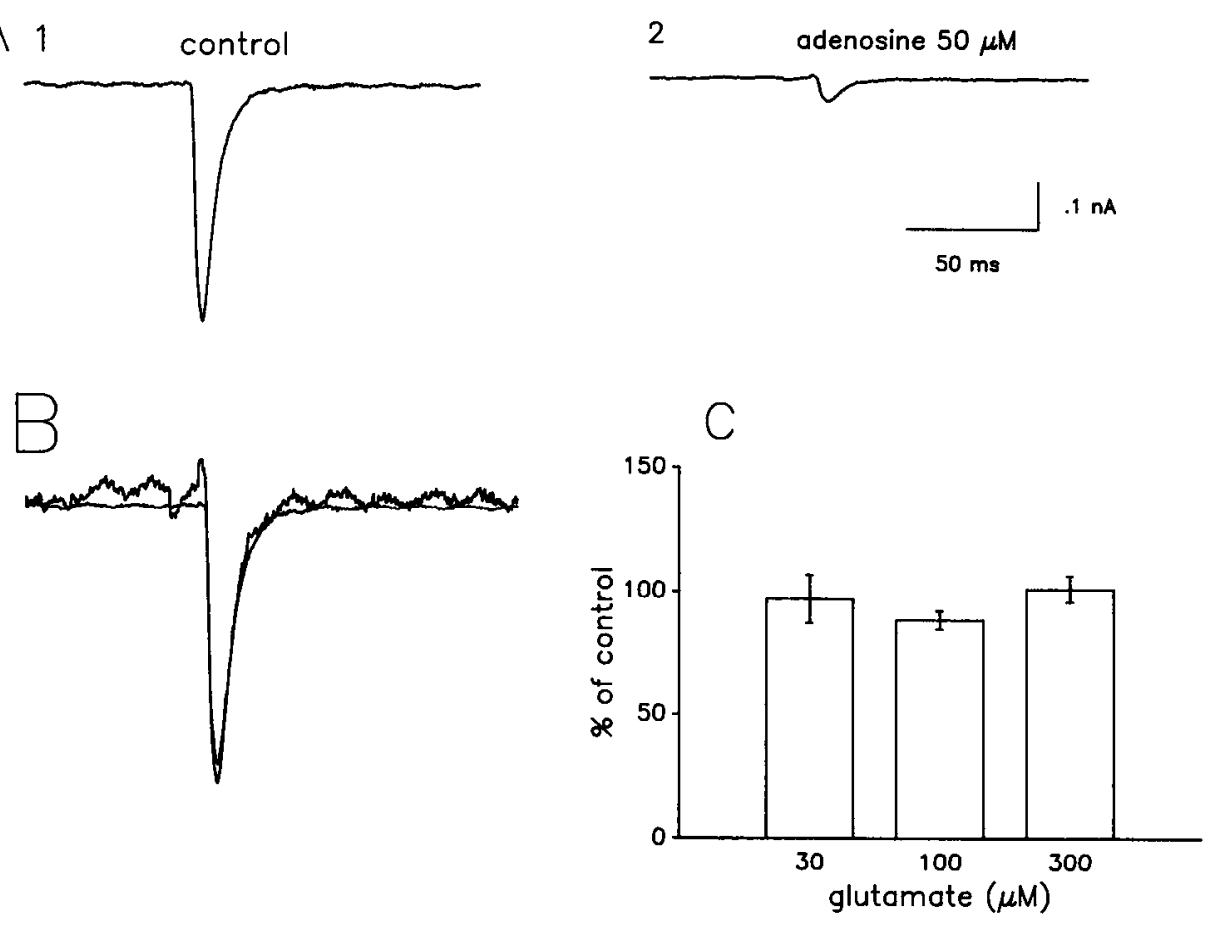

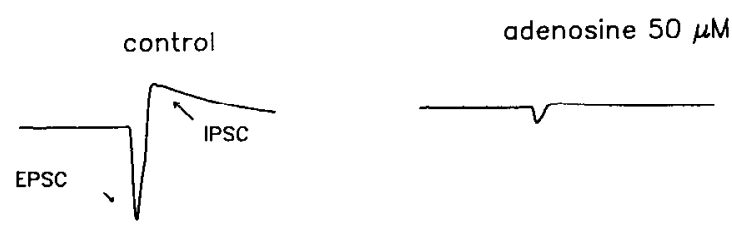

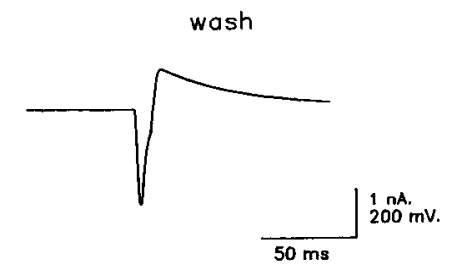

Figure 6. Adenosine indirectly inhibits IPSCs. This figure shows recordings from the same pair of cells as Figure 1. Adenosine indirectly blocks the disynaptic IPSC by reducing the EPSC that triggered its firing. munication). Likewise, the effect of baclofen on these channels, which is robust in the hippocampal slice (Andrade et al., 1986) is small or not even detectable in culture (Harrison, 1990).

Second, a variety of physiological and neurochemical experiments (Fredholm and Dunwiddie, 1988; Harrison, 1990) have consistently shown that these compounds have the capability of reducing transmitter release via a presynaptic action. Third, adenosine in our experiments had no effect on the currents elicited by direct postsynaptic glutamate application. Fourth, adenosine did not influence the time course of EPSCs, which would be expected if it modified postsynaptic cable properties. Fifth, baclofen had no effect on the IPSC reversal potential. We were not able to reverse EPSCs with either adenosine or baclofen under conditions that allowed us to maintain synaptic transmission.

Finally, Scholz and Miller (1991) have recently demonstrated that adenosine diminishes voltage-gated calcium currents in cultured hippocampal pyramidal neurons, but not in cultured hippocampal neurons, which stain for glutamate decarboxylase and are presumably inhibitory interneurons. This result correlates with our observations and suggests that adenosine could diminish excitatory transmitter release by blocking calcium currents in synaptic terminals. However, other possible mechanisms for synaptic modulation by adenosine, such as increase in potassium conductance (Trussell and Jackson, 1985, 1987), cannot be excluded at this time.

We have considered the possibility that adenosine could inhibit inhibitory transmission at sufficiently high concentrations, but we do not believe that this is very realistic. Because $10 \mu \mathrm{M}$ adenosine maximally inhibited EPSCs, the failure to diminish
IPSCs with $100 \mu \mathrm{M}$ suggests a true difference between excitatory and inhibitory neurons.

The clear-cut separation of adenosine and baclofen effects is intriguing, as others have suggested that their postsynaptic effects (increase in potassium conductance) are mediated by the same second-messenger systems (Nicoll, 1988). We cannot tell if our inhibitory neurons lack adenosine receptors at their terminals or only the coupling mechanism between receptors and ion channels.

While at least three previous reports have indicated that passive and active membrane characteristics of excitatory and inhibitory neurons differ (Schwartzkroin and Mathers, 1978; McCormick et al., 1985; Huettner and Baughman, 1988), there is only one well-documented example of such a qualitative difference in drug sensitivity between functionally distinct classes of central neurons. In that case, hippocampal inhibitory interneurons, but not pyramidal neurons, were hyperpolarized hy enkephalin (Madison and Nicoll, 1988). Interestingly, this suggests that opiates and adenosine may have functionally opposite roles in the hippocampus. Opiates can selectively excite pyramidal neurons in the hippocampus through their inhibition of inhibitory interneurons (Zieglgansberger et al., 1979), while adenosine dampens pyramidal excitability.

Regardless of the explanation for adenosine's selective reduction of excitatory transmission, the finding has potential therapeutic implications for problems such as epilepsy. Drugs related to adenosine that selectively block the release of excitatory transmitter, but fail to alter tonic release of inhibitory transmitter, might reduce seizure discharges more effectively than agents that nonspecifically diminish all transmitter release.
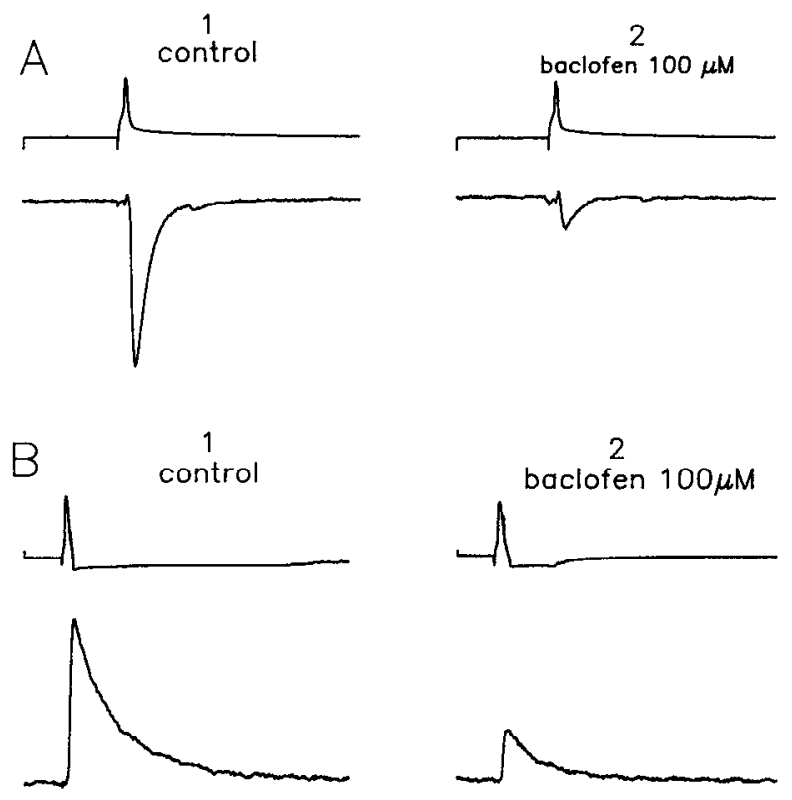

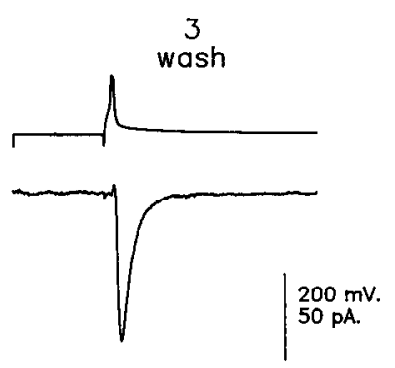

3

wash
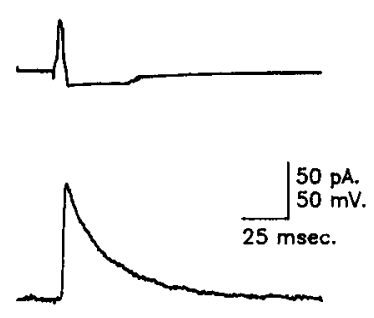

Figure 7. Baclofen inhibits both EPSCs $(A)$ and IPSCs $(B)$. In both sequences, the presynaptic action potentials are shown above the postsynaptic current responses. The time calibration is the same for $A$ and $B$. 

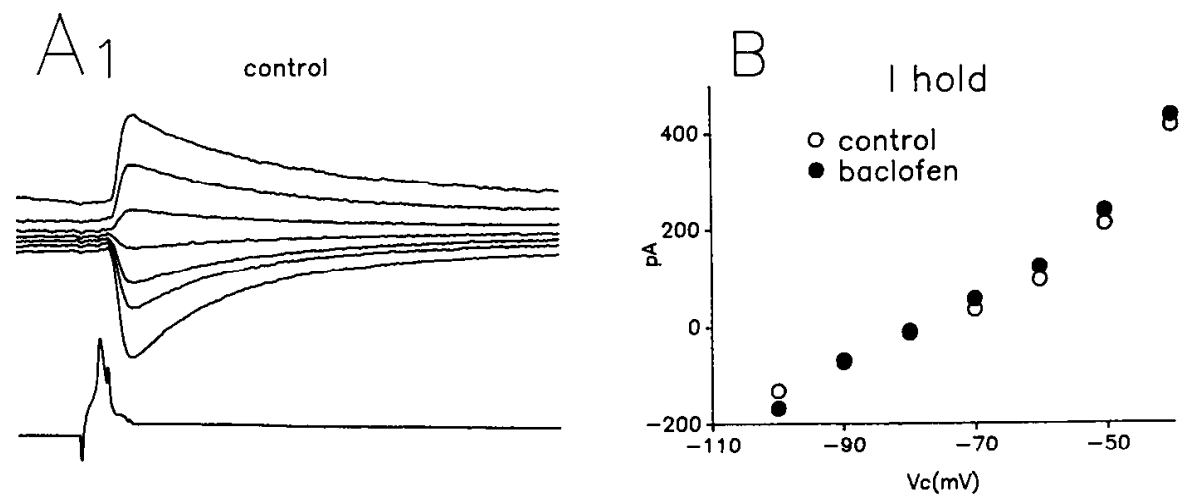

Figure 8. I-V plot of IPSC in the absence and presence of baclofen. $A_{I}$, IPSCs at holding potentials between -110 and $-40 \mathrm{mV}$. $A_{2}$, Same pair showing IPSCs with baclofen added. In both $A_{1}$ and $A_{2}$, each trace is the average of three responses. $B, I-V$ plot of holding current with and without baclofen. Each point is the average current of a 10 -msec segment preceding the action potential. $C$, Plot of peak IPSC in absence and presence of baclofen showing the baclofen-induced drop in synaptic conductance without alteration of reversal potential.
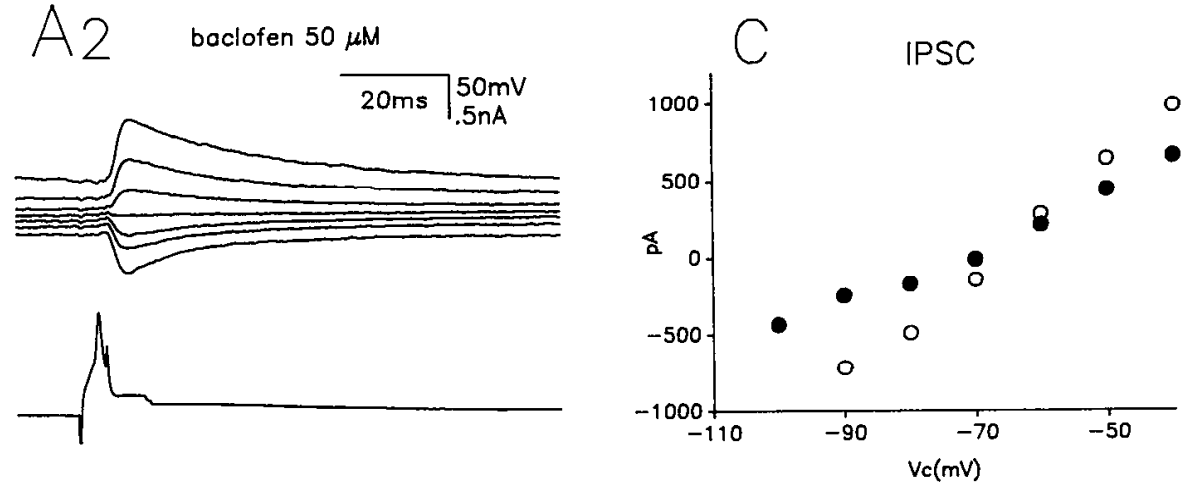

\section{References}

Andrade R, Malenka RC, Nicoll RA (1986) A G-protein couples serotonin and $\mathrm{GABA}_{\mathrm{B}}$ receptors to the same channels in hipposampus. Science 234:1261-1265.

Burke SP, Nadler JV (1988) Regulation of glutamate and aspartate release from slices of the hippocampal $\mathrm{CA}_{1}$ arca: cffects of adenosine and baclofen. J Neurochem 51:1541-1551.

Dolphin AC, Forda SR, Scott RH (1986) Calcium-dependent currents in cultured rat dorsal root ganglion neurones are inhibited by an adenosine analogue. J Physiol (Lond) 373:47-61.

Dunwiddie TV (1985) The physiological role of adenosine in the central nervous system. Int Rev Neurobiol 27:63-139.

Fredholm BB, Dunwiddie TV (1988) How does adenosine inhibit transmitter release? Trends Pharm Sci 9:130-134.

Fredholm BB, Proctor W, Ploeg IV, Dunwiddie TV (1989) In vivo pertussis toxin treatment attenuates some, but not all, adenosine $A_{1}$ effects in slices of the rat hippocampus. Eur J Pharmacol 172:249262.

Gerber V, Greene RW, Haas HL, Stevens DR (1989) Characterization of inhibition mediated by adenosine in the hippocampus of the rat in vitro. J Physiol (Lond) 417:567-578.

Hamill OP, Marty A, Neher E, Sakmann B, Sigworth FJ (1981) Improved patch-clamp techniques for high resolution current recordings from cells and cell-free membrane patches. Pfluegers Arch 391:85100.

Harrison NL (1990) On the presynaptic action of baclofen at inhibitory synapses between cultured rat hippocampal neurons. J Physiol (Lond) 422:433-446.

Hollins C, Stone TW (1980) Adenosine inhibition of $\gamma$-aminobutyric acid release from slices of rat cerebral cortex. Br J Pharmacol 69:107112.

Huettner JE, Baughman RW (1988) The pharmacology of synapses formed by identified corticocollicular neurons in primary cultures of rat visual cortex. J Neurosci 8:160-175.

Macdonald RL, Skerritt JH, Werz MA (1986) Adenosine agonists reduce voltage-dependent calcium conductance of mouse sensory neurones in cell culture. J Physiol (Lond) 370:75-90.
Madison DV, Nicoll RA (1988) Enkephalin hyperpolarizes interneurones in the rat hippocampus. J Physiol (Lond) 398:123-130.

McCormick DA, Connors BW, Lighthall JW, Prince DA (1985) Comparative electrophysiology of pyramidal and sparsely spiny stellate neurons of the neocortex. J Neurophysiol 54:782-806.

Nicoll RA (1988) The coupling of neurotransmitter receptors to ion channels in the brain. Science 241:545-551.

Rothman SM, Samaie M (1985) Physiology of excitatory synaptic transmission in cultures of dissociated rat hippocampus. J Neurophysiol 54:701-713.

Scholz KP, Miller RJ (1991) Analysis of adenosine actions on calcium currents and synaptic transmission in cultured rat pyramidal neurons. J Physiol (Lond) 435:373-393.

Scholz KP, Scholz WK, Miller RJ (1989) Effects of 2-Cl-adenosine on membrane currents and synaptic transmission in cultured rat hippocampal pyramidal neurons. Soc Neurosci Abstr 15:177.

Schubert P, Mitzdorf U (1979) Analysis and quantitative evaluation of the depressive effect of adenosine on evoked potentials in hippocampal slices. Brain Res 172:186-190.

Schwartzkroin PA, Mathers LH (1978) Physiological and morphological identification of a nonpyramidal hippocampal cell type. Brain Res 157:1-10.

Trussell LO, Jackson MB (1985) Adenosine-activated potassium conductance in cultured striatal neurons. Proc Natl Acad Sci USA 82: 4857-4861.

Trussell LO, Jackson MB (1987) Dependence of an adenosine-activated potassium current on a GTP-binding protein in mammalian central neurons. J Neurosci 7:3306-3316.

Westbrook GL, Pun RYK (1983) Baclofen suppresses excitatory transmission in spinal cord cultures by reducing quantal number. Neurology 33:62.

Yamada KA, Dubinsky JM, Rothman SM (1989) Quantitative physiological characterization of a quinoxalinedione non-NMDA receptor antagonist. J Neurosci 9:3230-3236.

Zieglgansbcrger W, French ED, Siggins GR, Bloom FE (1979) Opioid peptides may excite hippocampal pyramidal neurons by inhibiting adjacent inhibitory interneurons. Science 205:415-417. 